\title{
UMA TRAJETÓRIA ANTROPOLÓGICA: ENTREVISTA COM DIDIER FASSIN
}

\author{
Pedro Jaime \\ Universidade Presbiteriana Mackenzie - Brasil
}

\section{Ari Lima}

\section{Universidade do Estado da Bahia - Brasil}

Didier Fassin é um antropólogo francês, docente da École des Hautes Études en Sciences Sociales, onde fundou e coordena o Institut de Recherche Interdisciplinaire sur les Enjeux Sociaux (IRIS) e que em 2009 foi nomeado James D. Wolfensohn Professor do Institute for Advanced Study, da Princeton University. Ele lidera ainda um programa de investigações do European Research Council intitulado Towards a Critical Moral Anthropology. Esta seria uma apresentação sintética do nosso entrevistado. Ela certamente traz informações precisas, porém não faz jus à sua complexa trajetória.

Inusitadamente para a geração de profissionais já distantes dos fundadores da antropologia, Didier Fassin é um antropólogo e sociólogo cuja primeira área de formação e atuação profissional foi a medicina. Como médico, ao atuar na Índia e na Tunísia, decidiu pela conversão à sociologia e à antropologia. Algum tempo mais tarde, já como sociólogo e antropólogo, atuou como vice-presidente da ONG Médicos Sem Fronteiras. Tudo isso deu um caráter inovador ao seu percurso profissional, que é marcado pela proximidade entre a prática da pesquisa e a prática da intervenção. "O que há de mais interessante hoje nas ciências sociais se faz na fronteira entre a participação e a observação", declarou recentemente ao jornal Le Monde.

É possível perceber na antropologia praticada por Didier Fassin a influência de Georges Balandier, que dirigiu o seu doutoramento num período em que o estruturalismo de Claude Lévi-Strauss ainda era o paradigma antropológico hegemônico na França. Essa influência se evidencia na abordagem 
política que ele adota para analisar os fenômenos sociais. Contudo, se herdou essa perspectiva do seu mestre, não deixou de nutri-la também com a inspiração que encontrou em Pierre Bourdieu, na forma como este decodifica os mecanismos que produzem as desigualdades sociais; e em Michel Foucault, autor a quem descobriu em meados dos anos 1980 e com cuja obra nunca parou de dialogar.

Essas influências estão presentes em seu itinerário etnográfico. Elas se revelam nas investigações sobre a AIDS que realizou na África do Sul, juntamente com pesquisadores locais, e que resultaram na publicação do livro Quand les corps se souviennent: expériences et politiques du sida em Afrique do Sud (La Découverte, 2006), no qual interroga os corpos negros vitimados por essa epidemia. Aparecem também nos estudos empreendidos em seu próprio país, nos quais problematiza os significados de políticas públicas voltadas para os desempregados e os imigrantes, concebidos pelo Estado francês como corpos doentes ou perigosos.

Atualmente Didier Fassin vem participando ativamente dos debates sobre raça e racismo que têm sido objeto de calorosas polêmicas na França. Nos textos que escreveu a esse respeito, procurou revelar o viés racista e racialmente desigual da sociedade e do Estado franceses, paladinos de um ideal de universalidade e igualdade entre os homens. Para ele, não é mais possível camuflar, sob a máscara da xenofobia, o racismo existente naquele país. Os jovens franceses, nascidos na França de pais africanos, que recebem tratamento diferenciado não por possuírem status de estrangeiro, mas pela cor de sua pele, emergiram na cena pública protestando contra o destino que a República lhes reservava, algo que interpelou os sociólogos e antropólogos a se debruçarem sobre a questão racial a fim de compreender fenômenos como as revoltas juvenis ocorridas em Paris no ano de 2005. Das investigações que liderou a esse respeito resultaram duas coletâneas: De la question sociale à la question raciale? Représenter la société française (La Découverte), que coordenou com seu irmão, o sociólogo Éric Fassin, e que foi publicada inicialmente em 2006 e reeditada em 2009; e Les nouvelles frontières de la société française (La Découverte), lançado em 2010 com sua direção.

Outro eixo que orienta a sua produção antropológica mais recente concerne ao que denominou de governo humanitário, expressão que utiliza para 
se referir à introdução de sentimentos morais na vida política. A esse respeito, sua atenção tem se voltado para a reformulação que nos últimos anos marca o debate político. "As desigualdades são traduzidas como sofrimento social, as violências em termos de traumatismos e as questões políticas em termos humanitários", apontou ele também ao jornal Le Monde. Ademais, como ressalta nessa entrevista, considera que no mundo contemporâneo há uma zona de interseção nebulosa entre a ajuda humanitária e a intervenção militar. Isso porque, de um lado, a legitimação das intervenções militares é cada vez mais justificada pelo argumento humanitário; e, de outro lado, as próprias organizações não governamentais que atuam no campo humanitário adotam frequentemente a lógica de atuação própria dos exércitos. Os livros Contemporary states of emergency. The politics of military and humanitarian interventions (Zone Books), que ele organizou juntamente com Mariella Pandolfi; e La raison humanitaire: une histoire morale du temps présent (EHESS, Galimard/ Seuil), ambos publicados em 2010, refletem esse eixo de sua investigação científica.

$\mathrm{Na}$ entrevista que nos concedeu, Didier Fassin revela um pensamento crítico e erudito, sem abrir mão da clareza e sem as afetações que caracterizam muitas vezes as celebridades do mundo intelectual. Apresenta-se como um pesquisador orientado por autores clássicos da antropologia, da sociologia e das humanidades, compromete-se com a etnografia como fundamento da prática antropológica, mas também com uma perspectiva política em sua atuação como antropólogo. Ou seja, acredita na antropologia como ciência social, ratifica a importância do mundo acadêmico ao qual se filiou, apontando, contudo, para a necessidade de compreender e intervir na realidade social como ela se apresenta, para além do academicismo. Daí que propõe a antropologia em particular, e as ciências sociais em geral, como um modo de viver e um engajamento moral, que permitem refletir sobre questões sociais, sem desconsiderar os conflitos de ordem política e ideológica que os cercam e se posicionando em relação a eles.

Eis um perfil mais amplo do nosso entrevistado. Esperamos que por meio dessa conversação e das referências bibliográficas que trazemos o leitor brasileiro possa alargá-lo ainda mais, estabelecendo novos diálogos com este a quem consideramos um antropólogo inspirador. 
Pergunta: O senhor é apresentado comumente como antropólogo, sociólogo e médico. No entanto, terminou os estudos de medicina antes de fazer o doutorado em ciências sociais. Gostaríamos de começar por sua trajetória profissional e a passagem para a sociologia e a antropologia. Como se tornou sociólogo e antropólogo?

Didier Fassin: Provavelmente minha escolha de fazer medicina já comportava a antecipação de um questionamento antropológico e sociológico, já que decidi por essa orientação, talvez com um pouco de romantismo terceiro-mundista, ao descobrir as imagens terríveis da guerra de libertação do Bangladesh. Tendo me tornado médico na França, peguei uma licença no início dos anos 1980 para ir trabalhar no estado de Bengala, na Índia, e dessa vez realmente e fisicamente confrontado com a violência e a miséria nas ruas e favelas de Calcutá, esse duplo questionamento se encarnou nos corpos que eu tratava, nas faces que via, nas existências que descobria. Contudo, o que entendo por questionamento antropológico não é tanto a curiosidade pelo outro, isto é, o interesse por sua cultura; essa nunca foi minha maneira privilegiada de entrar na antropologia, sendo, aliás, algo de que frequentemente critiquei a inconsistência. O que entendo por questionamento antropológico é a interrogação mais existencial e radical sobre a vida daqueles bengalis que eu encontrava ou simplesmente cruzava. Eu me perguntava como eles viviam não com o distanciamento do antropólogo que recolhe um corpus de representações e de práticas, mas com o engajamento do antropólogo que tenta compreender, o mais perto de suas experiências cotidianas, os sujeitos por quem se interessa. Um interesse que é orientado menos pelo que esses sujeitos diferem, do que pelo que possuem em comum com o antropólogo. Da mesma forma, quando falo em questionamento sociológico, quero evocar não grandes arquiteturas teóricas, frequentemente pouco fundadas empiricamente, mas a articulação entre os efeitos da estrutura da sociedade e as margens de liberdade dos atores. Mais especificamente, de acordo com o olhar que então lançava sobre o mundo, eram as desigualdades sociais que me pareciam o mais urgente a analisar; elas ganhavam, no contexto indiano, uma expressão extrema da qual era difícil escapar. De resto, com o recuo possibilitado pelo tempo, pareceme que as proposições analíticas que tenho construído nos últimos anos em torno das políticas da vida (Fassin, 2009a), e mais recentemente da ética da sobrevivência (Fassin, 2010a), se conectam com as expectativas do meu início 
nas ciências sociais. Diria, mais exatamente, que essas proposições são uma espécie de resultado provisório, uma tentativa de combinar os dois questionamentos que me trouxeram à antropologia e à sociologia. Em síntese: tudo isso reflete um pouco minha resposta à exortação de Jacques Derrida, "aprender a viver enfim", uma vez que para mim as ciências sociais representam bem mais que uma atividade intelectual, elas são um modo de viver.

Pergunta: Quem são os antropólogos que, direta ou indiretamente, marcaram sua formação e nos quais o senhor encontrou inspiração para construir sua maneira de praticar a antropologia? Quais outros intelectuais, de diferentes campos do saber, o senhor reconhece como tendo uma influência importante na sua postura antropológica?

Didier Fassin: Certamente, como muitos antropólogos em flor, eu fui apresentado, quase convidado, à antropologia pela leitura de Tristes trópicos, livro no qual apreciei menos o exotismo do que a poesia, a sinceridade e a inteligência. Minha sensibilidade teórica, se podemos chamar assim, estava, no entanto, distanciada desse livro. Basta ler as páginas consagradas à Calcutá, o horror que manifesta o autor diante dessas multidões indianas e a desumanização a que ele lhes submete por meio de suas palavras, para constatar o quanto eu estava longe da estetização de Claude Lévi-Strauss que, ademais, meus amigos bengalis criticavam fortemente. A esse respeito minha proximidade era muito maior com Georges Balandier, com quem fiz minha tese de doutorado no fim dos anos 1980 e cujo livro Sociologie actuelle de l'Afrique noire estava bem mais relacionado com o nosso mundo e também com minhas próprias preocupações. A ideia que as sociedades que se denominava na época de "frias" possuem uma história, que essa história é política e nos envolve, e que, consequentemente, não há antropologia que esteja fora da política, nem que seja porque a antropologia é a herdeira de uma história, a da colonização em particular, isto me parecia em sintonia com o que eu descobria e com a posição que ocupava trabalhando como médico na Tunísia e depois como antropólogo no Senegal. Mas a revelação mais forte talvez me tenha vindo de Pierre Bourdieu, a partir da leitura de A distinção, que em meados dos anos 1980 meu irmão Éric havia me recomendado com grande entusiasmo. Subitamente tive a sensação de que a sociedade tornava-se inteligível, um pouco demais talvez, diria hoje. Aquela maneira de decodificar o mundo 
social e de desconstruir suas evidências respondia a uma expectativa que eu tinha de desnaturalizar o mundo. Poder apreender a complexidade dos mecanismos das desigualdades, os efeitos da dominação simbólica, os jogos do capital social, a força do habitus para iluminar mais de perto as representações e as práticas, estas eram questões pelas quais eu me interessava. Porém, o autor que mais me influenciou, ou que ao menos me acompanhou de maneira mais duradoura, não pertence ao campo das ciências sociais. É um filósofo: Michel Foucault (Fassin, no prelo). Comecei a lê-lo no fim dos anos 1980, em um momento em que ele não era mais atual na França e não tinha ainda voltado à moda. Desde então nunca parei de dialogar com sua obra, mesmo se, com o passar do tempo, esse diálogo se fez mais livre e mais crítico.

Pergunta: A sua trajetória é marcada por uma aproximação entre a pesquisa e a intervenção. O senhor foi vice-presidente da ONG Médicos sem Fronteiras. No artigo Une science sociale critique peut-elle être utile? (Fassin, 2009b), no qual faz um diálogo com a sociologia crítica de Pierre Bourdieu e a sociologia da crítica de Luc Boltanski, assim como com a sociologia pública de Michael Burawoy, o senhor retoma a metáfora platônica da caverna, afirmando que nas ciências sociais o pesquisador não se situa nem dentro nem fora da caverna, mas no limiar. Como vê a relação entre crítica e utilidade no trabalho do antropólogo?

Didier Fassin: A questão da crítica nas ciências sociais francesas me pareceu ter chegado a um impasse no início dos anos 2000. Por um lado, a sociologia crítica de Pierre Bourdieu e de seus alunos, da qual já afirmei o quanto sou devedor, tinha se transformado em uma máquina para denunciar, sendo difícil reconhecer o trabalho crítico rigoroso reivindicado em $O$ oficio de sociólogo. Por outro lado, a sociologia da crítica de Luc Boltanski e seu grupo, que havia tido o mérito de introduzir o pragmatismo na análise sociológica e consequentemente de estar mais atenta aos atores e à justificação de suas ações, resultou em uma renúncia do pensamento crítico, já que se tratava somente de propor gramáticas dos mundos sociais, como em La souffrance à distance. Além disso, em ambos os casos esses desenvolvimentos aconteceram ao mesmo tempo em que se produzia uma redução da importância atribuída ao material empírico e notadamente da pesquisa de campo, ou ao menos da sua restituição na escrita. Em outras palavras, o impasse no qual se encontrava 
a sociologia era o de se ver obrigada a escolher entre o olhar de cima, daquele que sabe o que os agentes sociais ignoram, em razão de estarem submetidos pela dominação ideológica; e a adesão à perspectiva dos atores sociais, ao ponto de conceber a análise como um exercício redundante ou mais precisamente uma simples tradução do que eles sabem melhor do que ninguém. $\mathrm{O}$ retorno à pesquisa de campo permitia defender outra postura teórica, que eu descrevi como "na fronteira". Se retomarmos a metáfora platônica da caverna, pode-se dizer que a sociologia crítica se situava do lado de fora, na claridade da luz solar, enquanto que a sociologia da crítica se colocava no interior, na obscuridade que fazia tomar as sombras como realidade. Eu defendo uma posição não intermediária, mas liminar, no limiar da caverna, ali onde um passo de um lado ou de outro conduz à luz ou à obscuridade. De maneira concreta, isso significa estar, ao mesmo tempo, suficientemente mergulhado em uma etnografia para poder dar conta honestamente da inteligência e da reflexividade dos atores, e bem distanciado em uma antropologia para ser capaz de desenvolver uma análise autônoma revelando o que escapa a esses mesmos atores. É no limiar da caverna que tento, por exemplo, desenvolver minha crítica da razão humanitária (Fassin, 2010b, 2011), trabalhando com as organizações não governamentais, mas ao mesmo tempo me esforçando para pensá-las em suas contradições e paradoxos.

Pergunta: No texto Le corps exposé. Essai d'économie morale de l'illégitimité (Fassin, 2004), o senhor afirma que durante muito tempo o corpo permaneceu como o ponto cego das ciências sociais, que pareciam resistir ao convite programático feito há mais de meio século por Marcel Mauss. Acrescenta que ao longo das últimas décadas, no entanto, a antropologia, assim como outras ciências humanas, influenciada pela obra de Michel Foucault, tem procurado entender o corpo como uma realidade social, produto de uma construção histórica e de representações culturais, objeto da invenção de saberes e lugar da manifestação de poderes. A quais razões o senhor atribui essas mudanças? Como compreende a centralidade que o corpo ganhou na teoria social contemporânea?

Didier Fassin: Por um curioso paradoxo, o corpo, cujo potencial heurístico os fundadores da ciência do social, no singular, tinham vislumbrado, se encontrava abandonado pela sociologia e pela antropologia durante uma 
grande parte do século XX. Lembremo-nos do belo texto sobre "a proeminência da mão direita", escrito por Robert Hertz em 1909 e da conferência programática de Marcel Mauss sobre "as técnicas corporais", de 1936, que abriam pistas fecundas. Foi somente a partir das últimas duas ou três décadas que o corpo se impôs como um objeto de pesquisa legítimo. E para compreender porque ele emergiu como um objeto de estudo legítimo é preciso primeiro analisar os obstáculos a essa emergência. Eles são ao menos de duas ordens. Inicialmente vale lembrar que o corpo foi naturalizado, ele pertencia mais à natureza do que à cultura, inclusive com o que alguns consideravam o caráter intransponível da diferenciação biológica dos sexos. Portanto, as ciências sociais pareciam ter pouco a dizer a seu respeito, deixando o terreno para as ciências naturais. Em seguida, cabe destacar que o corpo foi desvalorizado. $\mathrm{Na}$ visão dualista cartesiana que exprime o cogito, o espírito não apenas está separado do corpo, como é ele que constitui o ser humano, o que o aproxima de Deus, enquanto o corpo o liga ao reino animal e o compele à sua finitude material. Para as ciências sociais, descobrir, ou redescobrir, o corpo significou romper com essa dupla evidência. Os estudos sobre gênero e sexualidade desconstruíram a naturalidade do corpo, mostrando que mesmo as diferenciações mais inscritas na natureza eram também diferenças que a sociedade produzia. Quanto à reabilitação do corpo, ela veio da transformação das representações sociais construídas sobre ele, do lugar crescente que a arte, a dança, o cinema, o esporte, a medicina, mas também as revistas femininas e depois masculinas lhe atribuíram. Os estudos sobre o corpo se multiplicaram então desde uns 20 anos. A antropologia da saúde evidentemente desempenhou um papel importante, mas não exclusivo, nesse processo.

Pergunta: Nesse mesmo texto, o senhor afirma que o corpo foi mais frequentemente abordado pelas ciências humanas como a matéria sobre a qual se inscreve a norma e se manifesta a violência, do que apreendido a partir do que os indivíduos fazem com ele quando se veem confrontados com o Estado, a ciência, a medicina, a autoridade. Acrescenta então que a questão dos usos políticos do corpo se encontrou em larga medida subtraída da análise. A fim de contribuir para preencher essa lacuna e esboçar uma antropologia política do corpo, recorre a duas pesquisas que empreendeu. A primeira referente aos desempregados e trabalhadores precarizados que demandaram seguro de urgência ao Estado social, e a segunda tratando dos estrangeiros irregulares, 
sem documentação, que solicitaram vistos de residência ao Estado nacional (Fassin, 2000, 2001). Poderia nos dar uma visão geral das principais conclusões dessas pesquisas, bem como das linhas-mestras do programa da antropologia política do corpo tal como a concebe?

Didier Fassin: Existem numerosas maneiras de se interessar pelo corpo na perspectiva das ciências sociais. Pode-se abordá-lo em termos de representações (tradicionais ou contemporâneas), em termos de performances (do ritual ao teatro), em termos de normatização (através das prescrições da higiene ou da moral). Uma leitura que me parece importante e insuficientemente desenvolvida é a da antropologia política. Trata-se de compreender o que o Estado faz dos corpos ou o que ele faz aos corpos. Os dois estudos que conduzi na França sobre essa questão se referem a populações dominadas. No primeiro estudo abordei o caso dos desempregados e trabalhadores precarizados que estavam engajados em um protesto social contra a supressão de fundos do seguro financeiro. Para acabar rapidamente com as manifestações de rua e a ocupação de instituições públicas, o governo da época decidiu conceder auxílios extras. Para receber o dinheiro, que certamente era pouco, porém importante tendo em vista a pobreza dessas pessoas, era necessário escrever um breve texto justificando a demanda. Assim, indivíduos sem emprego, cujo $\mathrm{RMI}^{1}$ pago pelo Estado era inferior às despesas que tinham com habitação, água e eletricidade, foram instruídos a contar sua miséria e falar do seu sofrimento para poder receber uma bolsa modesta. No segundo estudo, enfoquei o caso dos estrangeiros em situação irregular, para os quais uma medida introduzida há alguns anos permitia a concessão de um visto de residência desde que sofressem de uma doença grave que não pudesse ser tratada em seu próprio país. Após serem submetidos a uma avaliação médica que confirmasse essa condição, eles tinham as suas situações regularizadas, por uma razão humanitária, dizia-se. Esse dispositivo se aplicava especialmente aos que solicitavam asilo, dentre os quais uma parcela cada vez maior era formada por pessoas cuja demanda havia sido rejeitada. Assim, tanto no caso dos desempregados quanto no caso dos estrangeiros, o Estado demandava que os

\footnotetext{
1 A sigla RMI se refere ao Revenu minimum d'insertion, uma política de redistribuição existente na França por meio da qual o governo garante uma renda mínima aos cidadãos que estão desempregados ou em situação de trabalho precário.
} 
solicitantes expusessem seus corpos (o corpo em sofrimento de uns, o corpo doente de outros) para obter o que lhes era concedido não como um direito, mas como um favor. Sugeri que tratássemos esse tipo de ação pública como políticas de compaixão.

Pergunta: Essa antropologia política do corpo é desenvolvida também no livro Quand les corps se souviennent. Expériences et politiques du sida en Afrique du Sud (Fassin, 2006c, 2007). O senhor apresenta esse livro dizendo que ele não se refere a um trabalho que poderia ser chamado de africanista enquanto campo especializado, mas a uma antropologia geral que aborda questões relativas à dinâmica do "viver junto", não somente na sociedade sul-africana, mas na sociedade global, na qual as injustiças e as divergências encontram primeiramente suas fontes no pensamento que lhes ignora e lhes justifica. Acrescenta que essa obra trata de questões de corpo e de memória, de experiência e de políticas. As políticas de Estado e a política dos sujeitos, as políticas de vida e de morte. O que a história da AIDS na África do Sul pósapartheid nos ensina sobre o mundo contemporâneo?

Didier Fassin: O que está em jogo para a antropologia é na verdade demonstrar que as questões que a disciplina trata em contextos particulares e por vezes distantes têm um significado mais amplo, indo além do quadro no qual as pesquisas são realizadas. Isso foi algo que Claude Lévi-Strauss e Clifford Geertz conseguiram no tempo deles ao mostrarem que a abordagem estrutural, para um, e interpretativa, para o outro, não serviam apenas para compreender os mitos da Amazônia e a briga de galos em Bali respectivamente, mas tornavam-se instrumentos para decifrar nosso mundo. Essa demonstração é talvez mais difícil de fazer quando se leva em conta, bem mais do que eles fizeram em seus trabalhos, as dimensões histórica e política que, por definição, parecem circunscrever o objeto em uma conjuntura singular. Parecia-me necessário então que, falando da AIDS na África do Sul, eu mostrasse em que os ensinamentos que retirava de minha pesquisa tinham uma abrangência geral. Esse país estava enfrentando uma dupla crise de inteligibilidade. Por um lado, ninguém era capaz de entender a pavorosa explosão da AIDS, cujos índices de infecção haviam passado de menos de 1\% em 1990 para mais de 20\% em 1999, isso mesmo quando o país finalmente acabava de aceder pela primeira vez na sua história à democracia. Por outro lado, as declarações do presidente 
sul-africano e de sua ministra da saúde sugerindo que a AIDS devia-se mais à pobreza do que a um vírus e que os tratamentos antirretrovirais eram no mínimo ineficazes, ou até mesmo perigosos, soavam para muitos como irracionais, especialmente porque recebiam o apoio de parte importante da população negra. Para dar conta dessa dupla realidade, tão difícil de apreender, utilizei o conceito de incorporação da história. É preciso entender a incorporação da história, isto é, a inscrição do passado nos corpos, em uma dupla dimensão: objetiva e subjetiva. De um lado, trata-se da incorporação das estruturas sociais herdadas do passado. A pobreza e a violência, em particular, são para muitos a base da progressão tão rápida da AIDS, algo que a abertura das fronteiras que confinavam as populações africanas em townships e bantustans acelerou ainda mais. Nas minas, a própria organização do trabalho com a concentração de homens, separados de suas famílias que permaneciam nas vilas, em acampamentos em cuja proximidade havia lugares onde a bebida e o prazer era fácil criou condições quase experimentais de disseminação da AIDS. De outro lado, é a incorporação da memória dos sofrimentos e das desconfianças do passado. A medicina e as ciências em geral são particularmente suspeitas, uma vez que sua cumplicidade com a supremacia branca desempenhou um papel importante na construção e justificação da segregação racial. Falar de incorporação da história é então reunir em um mesmo conceito o que permite interpretar, certamente não de forma mecânica, o desenvolvimento da epidemia na população negra e a propagação de teorias da conspiração. Evidentemente esse conceito não se limita unicamente ao contexto sul-africano. Ele é válido em várias situações históricas, sobretudo pós-coloniais. Ademais, prolonguei em seguida essa pesquisa me deslocando do corpo físico ao corpo psíquico, se posso ousar dizer, estudando com meu amigo Richard Rechtman as condições nas quais o trauma se tornou nas sociedades contemporâneas a última pista de um evento. Aquela por meio da qual se pode atestar que uma violência foi produzida, demandar a sua reparação, construir sobre ela um testemunho. Nós damos conta assim do aparecimento do que denominamos de condição social de vítima (Fassin; Rechtman, 2007, 2009).

Pergunta: Em outra publicação (Fassin, 2008b), o senhor aborda o contexto de produção da pesquisa que resultou no livro Quand les corps se souviennent. Afirma que essa pesquisa foi empreendida no quadro de uma parceria científica entre a França e a África do Sul. Tratava-se, acrescenta, de 
uma colaboração que não era óbvia e na qual houve tensões entre pesquisadores estrangeiros e locais. Poderia nos falar um pouco sobre a complexidade desse projeto coletivo?

Didier Fassin: As condições da pesquisa antropológica mudaram bastante ao longo das últimas décadas. As sociedades, grupos ou instituições que estudamos estão mais desconfiados de nós e mais exigentes quanto às questões éticas e políticas de nossos trabalhos. É preciso ver nisso algo positivo, mesmo se conduz por vezes a obstáculos prejudiciais à pesquisa. No caso do meu trabalho na África do Sul, me deparei com dois tipos de dificuldades. Por um lado, em um contexto extremamente polarizado em torno da AIDS, com ativistas apoiados por ampla parcela dos pesquisadores, dos intelectuais e da população branca, que se opunha ao governo, que, por sua vez, era defendido pela grande maioria da população negra, meu trabalho consistia, ao invés de escolher entre os dois lados da disputa, tentar objetivar as posições de uns e de outros para dar conta do drama social, no sentido de Victor Turner, que representava a controvérsia sobre a AIDS. Essa posição só podia desagradar às duas partes. Mas, se fui criticado por ambas quando meu livro fui publicado em inglês, também recebi retornos muito favoráveis, tanto fora da África do Sul quanto no país, de pesquisadores e de cidadãos que me disseram que somente um estrangeiro poderia escrever um livro daqueles. Acredito na verdade que o distanciamento do olhar autoriza uma liberdade de pensamento e de escrita que os atores locais não têm, por estarem presos nas dinâmicas e lutas locais. Por outro lado, as dificuldades que fizeram parte da minha experiência se manifestaram no quadro da cooperação com colegas sul-africanos. Eu devo muito a essas pesquisas que realizamos juntos no Hospital Geral de Soweto, que é o maior da África, onde nós trabalhamos sobre as questões éticas e morais na assistência aos pacientes. Penso que essa coprodução da pesquisa é um elemento importante da redefinição das práticas científicas da antropologia. Ela traz, entretanto, problemas diversos, tendo em vista o olhar dos observadores estrangeiros e dos nacionais sobre as mesmas realidades (a compreensão que possuem e a crítica que se autorizam) e, ao mesmo tempo, as posições que ambos ocupam (os pesquisadores nacionais estando envolvidos em engajamentos institucionais, profissionais e políticos que os pesquisadores estrangeiros não possuem). Essas tensões estiveram presentes quando da escrita e, sobretudo, da publicação de um artigo que meus colegas julgavam 
crítico demais. Ao invés de me resignar ao que poderia ser visto como um fracasso, decidi fazer daquilo objeto de análise. De maneira geral, considero que a pesquisa não acaba com a conclusão do trabalho de campo ou a publicação de um livro, ela prossegue nas trocas e por vezes nos desacordos e conflitos que acontecem após o término de um e o aparecimento do outro. $\mathrm{O}$ trabalho antropológico deve integrar tanto as condições de sua produção quanto de sua recepção.

Pergunta: No texto L'inquiétude ethnographique (Fassin, 2008a), refletindo sobre os desafios epistemológicos, éticos e políticos que se colocam à pesquisa etnográfica no mundo contemporâneo, o senhor aponta que a influência de Wittgenstein e Foucault, o impacto dos estudos subalternos e dos estudos feministas, o diálogo com a literatura e a crítica literária, assim como a contestação, pelos membros das sociedades ou grupos estudados, do empreendimento de reificação que eles afirmam terem sido conduzidos às suas custas, participaram fortemente do movimento de redefinição do status da etnografia na construção do saber antropológico. Acrescenta que esse movimento é certamente menos perceptível na França do que nos Estados Unidos. Em sua opinião, quais são as razões da existência dessa diferença entre os dois países?

Didier Fassin: A antropologia francesa, confiante na herança de seus mestres, de Claude Lévi-Strauss à Georges Balandier, passando por Louis Dumont, olhou com ar de ironia e crítica para o desenvolvimento de teorias novas do outro lado do Atlântico, qualificando-as apressadamente como pósmodernas, subestimando assim duas coisas. Primeiramente que elas não eram propriamente estadunidenses. $\mathrm{Na}$ verdade, ou eram provenientes dos países anteriormente colonizados, como os estudos subalternos na Índia ou a crítica literária de um Edward Said, ou tinham sido adotadas na América do Norte, mas sendo procedentes de outros lugares, a começar pelas filosofias de Wittgenstein e de Foucault. Em seguida, que elas tinham uma perspectiva epistemológica, ética e política muito maior do que se imaginava, comprometendo os fundamentos do regime de conhecimento subjacente às monografias etnográficas e teorias antropológicas. É nesse período que a antropologia francesa se fechou para o mundo, enquanto que a antropologia estadunidense se questionava, por vezes de maneira excessiva, como resultado das críticas internas (a virada interpretativa) e externas (a revolta dos "nativos"). 
O empreendimento etnográfico, que é o coração da singularidade antropológica, foi também o centro dessa convulsão, já que de Writing Culture aos aborígenes da Austrália, a autoridade etnográfica se viu contestada. Longe de enfraquecer o papel da etnografia, essa dupla crítica, interna e externa, permitiu que se colocassem novas questões, que se convidasse a uma nova ética, que se propusesse finalmente outra política da pesquisa como nós tentamos defender com um grupo de estudantes no livro citado.

Pergunta: Voltando ao livro Quand les corps se souviennent, nesse trabalho o senhor analisa as controvérsias entre o governo e a sociedade a respeito do combate à epidemia da AIDS e indica que, nessas controvérsias, houve denúncias recíprocas que utilizavam uma temática racialista. Poderia nos dizer como a questão racial fazia parte das disputas relativas a essa política de saúde na África do Sul?

Didier Fassin: A questão racial e mesmo racista está evidentemente no centro da história sul-africana. O período do apartheid, entre 1948 e 1994, representa para muitos a expressão mais pura e mais extrema do racismo de Estado. Mas a política racial começa desde a colonização do país no século XVII, se acentuando no fim do século XIX com a descoberta do ouro e do diamante, que conduziu a uma exploração feroz nas minas da mão de obra de trabalhadores, em sua maioria negros. A segregação racial se estabelece a partir de 1900 por ocasião da epidemia da peste. Tão longa e dolorosa história não se apaga da noite para o dia, como após 1994 alguns acreditavam, ávidos que estavam para pôr fim a algo de que eram frequentemente cúmplices. Foi grande o mérito dos governos do período pós-apartheid, a começar pelo de Nelson Mandela, de ter buscado ultrapassar as divisões do passado construindo uma sociedade não racial; e foi notável o esforço daqueles que conceberam a Comissão Verdade e Reconciliação, sobretudo o bispo Desmond Tutu, de tentar edificar o futuro sobre o perdão em vez do esquecimento. Mas a AIDS reabriu feridas do apartheid que ainda não estavam cicatrizadas, porque os negros se encontravam mais uma vez não somente como os mais contaminados pela epidemia, mas também como os mais estigmatizados. A epidemia foi o revelador desse passado que não passava, se assim podemos dizer. Uma economia moral do ressentimento e da suspeita dividiu novamente a sociedade sul-africana segundo uma linha racial que a controvérsia reforçou ainda mais já que a maioria 
dos negros apoiou o governo da ANC enquanto que a maior parte dos brancos se colocava contra o poder. Certamente a temática racial foi instrumentalizada por ambos os lados, o poder acusando seus opositores de ter mais uma vez um comportamento racista; os opositores, por seu turno, denunciando a racialização cínica de um problema de saúde pública. Em suma, a AIDS desvelou uma verdade histórica que a sociedade se esforçara para enterrar.

Pergunta: Gostaríamos de continuar falando da questão racial, mas abordando agora a França, ao invés da África do Sul. Em 2002 o senhor publicou um artigo intitulado L'invention française de la discrimination (Fassin, 2002). Num capítulo do livro De la question sociale à la question raciale? Représenter la société française (Fassin, 2006a), retoma esse ponto. Afirma então que as discriminações raciais foram inicialmente invisibilizadas, depois recusadas na sociedade francesa ao longo do último meio século. Quais são as razões que, em sua opinião, explicam essa invisibilização e essa recusa que durante tanto tempo marcaram o tratamento da questão racial na França?

Didier Fassin: A linguagem das discriminações e mais precisamente ainda com o qualificativo racial aparece no espaço público na França somente no final dos anos 1990. O caráter tardio desse reconhecimento é bastante marcante, sendo necessário explicá-lo. É claro que as discriminações raciais existiam antes de serem nomeadas. Os imigrantes italianos e poloneses no início do século XX, magrebinos e subsaarianos depois da segunda guerra mundial, foram vítimas de discriminação racial. Mas por um lado, na medida em que se tratava em sua maioria de imigrantes, falava-se mais de xenofobia. E por outro lado, quando atos criminosos eram cometidos ou posturas estigmatizantes assumidas, eram qualificados como racistas. Todavia, frequentemente ignoraram-se essas práticas, quer enfatizando-se o modelo republicano de integração (que se considerava, sobretudo à direita, que funcionava muito bem), quer relacionando as anomalias a questões de classe social (essas populações eram certamente menos bem tratadas, mas é porque pertenciam ao proletariado, dizia-se dessa vez à esquerda). A discriminação racial tal como apareceu no final dos anos 1990 rompe com essa dupla negação e com o duplo referencial da xenofobia e do racismo. De um lado, o reconhecimento das discriminações não necessita de avaliação de intenção: pode-se não contratar uma pessoa ou não lhe alugar um apartamento independentemente de qualquer intenção 
racista, porque se tem medo das reações dos clientes ou dos locatários. A discriminação é um tratamento desfavorável que é condenável como tal, sem que seja necessário identificar o preconceito racista. Ela pode até ser medida estatisticamente e fala-se nesse caso de discriminação indireta. De outro lado, a interpretação das discriminações não se faz no nível individual, mas coletivo. É um fenômeno social que não pode ser reduzido à incriminação de uma pessoa e deve ser apreendido no nível estrutural, em particular as discriminações institucionais que colocam em causa um dispositivo amplo, tal como a instituição policial, e não simplesmente o indivíduo, nesse caso o policial. Essa mudança de paradigma (da xenofobia e do racismo para a discriminação racial) está ligada a três tipos de razões. Primeiramente, a mobilização de atores associativos e pesquisadores, e mais tarde de sindicatos e partidos, permitiu que se reconhecesse a existência de um fenômeno até então ignorado. Em segundo lugar, a harmonização das políticas e das regulamentações europeias forçou o governo francês a levar em conta questões que ele não queria admitir. Em terceiro lugar, a evolução demográfica com o aumento de adolescentes e jovens franceses, nascidos na França de pais africanos, cujo tratamento desfavorável não poderia mais ser colocado na conta do seu status de estrangeiro e que começaram a protestar contra o destino que a República lhes reservava. É na virada dos anos 2000 que acontece essa mudança de paradigma.

Pergunta: Essa questão é abordada também na coletânea sobre as novas fronteiras da sociedade francesa que o senhor coordenou (Fassin, 2010c). Na introdução, retomando do inglês a distinção entre border e boundary, o senhor afirma que o objetivo do livro é examinar as fronteiras externas e internas da França contemporânea. Isto é, de um lado os limites do território nacional ou supranacional europeu que separam juridicamente os cidadãos nacionais dos estrangeiros ou, desde a criação da União Europeia, os cidadãos da comunidade europeia daqueles que não pertencem a esta comunidade; e de outro lado os limites entre categorias sociais racializadas herdeiras de uma dupla história, da colonização e da imigração. Poderia apresentar em linhas gerais as reflexões empreendidas pelos pesquisadores que participaram desse projeto e suas principais conclusões?

Didier Fassin: Esse livro é na verdade o resultado de um programa de pesquisa desenvolvido ao longo de vários anos reunindo cerca de 40 pesquisadores. Gostaria de destacar quanto a isso que uma das evoluções significativas 
nas ciências sociais, inclusive na antropologia, se refere à constituição de coletivos de pesquisadores e estudantes. Certamente existe sempre uma parte substancial de nossa atividade que se exerce de maneira relativamente solitária, no campo ou em um gabinete, durante a pesquisa empírica ou no período da escrita. Porém, temos mais frequentemente do que no passado momentos comuns de construção de problemáticas, de discussão de métodos, de confrontação de resultados e de interpretações, associando não apenas colegas, mas também doutorandos que avançam assim sua formação. Voltando a essa pesquisa sobre as fronteiras, nos interessamos por um fenômeno até então relativamente pouco identificado como tal: a superposição de fronteiras externas (borders), territoriais e legais, que definem a nação e a nacionalidade; e de fronteiras internas (boundaries), sociais e raciais, que distinguem os grupos entre si. Na verdade, há ao mesmo tempo superposição e frequentemente confusão de fronteiras. Assim, por ocasião das rebeliões do outono de 2005, que tive a oportunidade de estudar, o fato de os adolescentes e jovens revoltados após a morte de dois deles perseguidos pela polícia serem, em sua maioria, negros e árabes fez como que se falasse de revoltas raciais, termo que jamais havia sido usado antes. Contudo, o presidente da república, Jacques Chirac, e seu ministro do interior, Nicolas Sarkozy, se apressaram a relacionar o problema a uma questão de imigração, anunciando o reforço das políticas de controle nas fronteiras e de expulsão de estrangeiros em situação irregular, quando na verdade as pessoas interpeladas pela polícia eram francesas nascidas na França. De maneira geral a análise da dupla fronteira que eu propus permite uma interpretação da sociedade francesa, mas também de outras. Assim, no quadro do programa Borders and Boundaries que coordenei com meu irmão Éric em colaboração com a Columbia University em Nova Iorque, ficamos surpresos por constatar a maneira quase invertida como as questões se colocavam na França e nos Estados Unidos. No primeiro caso, as fronteiras externas se impuseram primeiro e as fronteiras internas foram reconhecidas tardiamente. No segundo, as fronteiras internas são antigas, com a escravidão, a segregação e o racismo, enquanto as fronteiras externas, sobretudo com o vizinho mexicano, se tornaram um problema apenas recentemente. A articulação das duas fronteiras se faz então de forma diferente em função dos contextos nacionais.

Pergunta: Em um capítulo publicado no livro De la question sociale à la question raciale? (Fassin, 2006b), o senhor afirma que ao lado da clássica combinação do racismo racial, existe uma racialização não racista, mas 
também um racismo sem raça. No capítulo que escreve para Les nouvelles frontières de la société française (Fassin, 2010d), aprofunda a reflexão sobre o conceito de racialização. Nesse texto, fazendo referência a Michael Banton, Paul Gilroy e Alli Rattansi, o senhor diz que mesmo se esse conceito traz problema, ele tem a sua importância. Poderia precisar sua compreensão das ideias de raça, racismo e racialização?

Didier Fassin: Em primeiro lugar, vale a pena mencionar que as raças não existem. No entanto, é inegável que certas pessoas formulam discursos e conduzem ações como se elas existissem. Pode ser para rebaixar, humilhar, discriminar, separar, exterminar. Falamos nesse caso de racismo. Pode ser para designar, reivindicar, contar. Falamos então de racialização. Do ponto de vista analítico, como do ponto de vista moral, o racismo não representa um problema, pois sabemos que ele procede de uma inferiorização ou uma negação do outro racializado e geralmente concordamos em considerar que se trata de uma prática a ser condenada, inclusive nos tribunais. Já a racialização é mais problemática, ao mesmo tempo em uma perspectiva analítica (O que ela significa? O que nos permite dizer?) e moral (É ruim utilizar a linguagem racial? Como avaliar particularmente esta linguagem quando é utilizada por aqueles a quem se discrimina?). Propus então, no texto ao qual vocês fazem referência, a distinção entre três modalidades de racialização, me apoiando sobre os três pronomes pessoais. Na primeira pessoa, eu te atribuo uma condição racial, frequentemente para te discriminar, eu te privo de um direito (de um emprego ou de uma habitação, por exemplo), porque te vejo como um negro ou um árabe. Na segunda pessoa, tu te reconheces e reivindicas essa identidade que te foi imposta. Tu participas de uma associação negra para melhor combater as discriminações. Na terceira pessoa, ele qualifica ou quantifica esta situação. Assim, o jornalista nomeia o problema e o demógrafo o mede. Franz Fanon e, antes dele, W. E. B. Du Bois mostraram o caráter polissêmico da racialização e a complexidade da interação na qual aquele que é marcado (“Olha, um negro!”) se reconhece (“Eu que sou vítima de discriminação enquanto negro"). Na França, a descoberta das discriminações raciais revelou a primeira pessoa, a constituição do CRAN (Conselho Representativo das Associações Negras) deu realidade à segunda pessoa, o debate em torno das estatísticas étnicas mostrou o caráter potencialmente polêmico da terceira pessoa. Em resumo: a racialização é um instrumento analítico não para certificar a ideia de raça, mas para dar conta das disputas em torno da 
questão racial que se desenrolam hoje. Não é o pesquisador que cria essa realidade e, mesmo se ele lamenta sua existência, lhe cabe explicá-la.

Pergunta: Em 2010 foi publicada nos Estados Unidos, sob sua coordenação, uma obra coletiva que, a partir da análise de operações concretas conduzidas nos cinco continentes, interroga os limites imprecisos entre a ajuda humanitária e a ação militar no mundo pós-guerra fria (Fassin; Pandolfi, 2010). Quais são as principais reflexões sobre situações de emergência no mundo contemporâneo empreendidas pelos antropólogos, cientistas políticos, juristas e ativistas que participam desse projeto?

Didier Fassin: O governo humanitário, como proponho denominar, se refere à introdução de sentimentos morais na vida política. Ainda que a genealogia humanitária remonte ao final do século XVIII com a luta pela abolição da escravatura, especialmente na Inglaterra; e ao final do século XIX com a criação da Cruz Vermelha para proteger os civis e os feridos nos campos de guerra, foi durante as últimas décadas que esse governo se tornou ao mesmo tempo não governamental (as associações como Médicos sem Fronteiras e Médicos do Mundo) e governamental (os Estados e a ONU). A legitimação das intervenções militares, sobretudo quando elas não são legais no que diz respeito às regras e à votação da ONU, é cada vez mais justificada pelo argumento humanitário. De maneira cada vez mais frequente uma confusão se estabelece entre o militar e o humanitário. Os governos não são os únicos responsáveis por essa confusão. As próprias organizações não governamentais adotam por vezes a temporalidade, a inscrição espacial, o estilo de ação e mesmo os objetivos dos exércitos. É então essa ordem moral do mundo que nós estudamos, não para lê-la de maneira simplificadora, mas para compreender suas contradições e paradoxos.

Pergunta: Em 2009 o senhor foi nomeado James D. Wolfensohn Professor do Institute for Advanced Study, da Princeton University, instituto onde Clifford Geertz, um dos mais eminentes antropólogos do século XX, desenvolveu uma parte importante do seu trabalho. Qual o sentido dessa nomeação para a antropologia francesa, em um contexto no qual, desde os anos 1980, após um período de hegemonia do paradigma estruturalista, a teoria antropológica a despeito de sua internacionalização e de certa descentralização é marcada principalmente pela produção estadunidense? 
Didier Fassin: Mesmo sendo difícil julgar objetivamente uma situação na qual se está diretamente envolvido, penso que o sentido da minha nomeação (uma vez que esse é o único grande estabelecimento do mundo acadêmico norte-americano onde não se é candidato, não se é eleito, mas nomeado) corresponde precisamente a um desejo dos professores de ciências sociais do Institute for Advanced Study de Princeton de renovar os territórios da antropologia e não de assegurar sua reprodução. Ao invés de perpetuar uma tradição intelectual, como fez o Collège de France, nomeando sucessivamente para a cadeira fundada por Claude Lévi-Strauss, dois antropólogos que foram seus alunos, Françoise Héritier e Philippe Descolas, meus colegas preferiram aos discípulos de Clifford Geertz, cuja presença na antropologia norte-americana é profunda, um outsider, no duplo sentido da palavra: alguém que vem de fora e que não é esperado. Essa escolha me parece ainda mais significativa pelo fato de eu ser o primeiro não estadunidense nomeado na School of Social Science. Suponho que é preciso ver nisso tanto um reconhecimento de certa antropologia francesa, quanto uma abertura de espírito que privilegia a ruptura e, espero, a inovação sobre a continuidade. Duas coisas, disseram-me, foram importantes na decisão de me recrutar. Por um lado, o trabalho crítico que reivindico e que se volta tanto para o objeto das ciências sociais quanto para as ciências sociais em si mesmas. Por outro lado, a pesquisa empírica sobre a qual se apoia meu trabalho teórico, algo que as evoluções textualistas e pragmatistas das ciências sociais tinham conduzido um pouco ao esquecimento. Mas, acima de tudo, devo dizer que considero essa confiança em mim depositada, ao me nomearem para a cadeira de antropologia a fim de suceder Clifford Geertz, como um grande desafio e espero ser digno dessa honra. Darei prosseguimento a esse programa de uma antropologia política e moral, cujas linhas gerais apresentei aqui por meio da discussão dos meus trabalhos, no Institute for Advanced Study, que é um lugar não somente onde as condições de pesquisa são ótimas, mas também de onde é possível fazer ouvir a voz das ciências sociais e reconhecer um projeto de antropologia crítica.

Pergunta: O antropólogo Claude Lévi-Strauss disse certa vez que o século XXI será o século das ciências humanas, ou não será. Em sua opinião, qual é o lugar da antropologia neste século? Quais são os maiores desafios da disciplina em sua constante reinvenção, dessa vez em um contexto cada vez mais transnacional? 
Didier Fassin: Seria bom acreditar na profecia de Claude LéviStrauss. Entretanto, certamente não é suficiente anunciá-la para que se realize. Inversamente, podemos pensar no grito de alerta lançado por Martha Nussbaum a respeito do recuo do ensino das "humanidades" na educação em detrimento de abordagens mais diretamente orientadas para a produção, o crescimento, a rentabilidade. Esperemos que no final das contas o antropólogo francês tenha razão contra a filósofa estadunidense... Mas eu estou sinceramente e seriamente convencido de que as ciências sociais em geral, e a antropologia em particular, têm um papel importante a desempenhar e um lugar eminente a ocupar no mundo de amanhã. Isso supõe é claro que a sociedade escute o que temos a dizer, mas supõe igualmente que sejamos exigentes sobre o que dizemos. Quanto a isso, dois cuidados me parecem decisivos. Primeiramente a antropologia não deve renunciar a seus princípios. Como se diz no esporte é preciso "retomar os fundamentos". A etnografia é certamente o mais importante. Ela por vezes tem sido esquecida. A exploração dos territórios vizinhos da filosofia e da literatura não deve nos levar a abrir mão da ideia de que é a pesquisa empírica que funda a legitimidade e mesmo certa verdade de nosso saber, desde que, é claro, a alimentemos com nossa reflexão teórica. Em seguida, a antropologia deve tornar as sociedades contemporâneas inteligíveis. Daí decorre a importância, certamente sem exclusividade, que atribuo à história e à política em nosso trabalho. Essa inteligibilidade exige que não renunciemos jamais a exercer nosso pensamento crítico sobre o mundo, mas também sobre a maneira como o estudamos. Com essa dupla condição a antropologia me parece ter, como se diz, belos dias pela frente.

\section{Referências}

FASSIN, D. La supplique. Stratégies rhétoriques et constructions identitaires dans les demandes d'aide d'urgence. Annales: Histoire, Sciences sociales, v. 55, n. 5, p. 955-981, 2000.

FASSIN, D. Quand le corps fait loi. La raison humanitaire dans les procédures de régularisation des étrangers. Sciences sociales et santé, v. 19, n. 4 , p. 5-34, 2001. 
FASSIN, D. L'invention française de la discrimination. Revue française de science politique, v. 52, n. 4, p. 395-415, 2002.

FASSIN, D. Le corps exposé: essai d'économie morale d'illégitimité. In: FASSIN, D.; MEMMI, D. (Dir.). Le gouvernement des corps. Paris: Éditions de l'EHESS, 2004. p. 237-266.

FASSIN, D. Du déni à la dénégation. Psychologie politique de la représentation des discriminations. In: FASSIN, D.; FASSIN, E. (Dir.). De la question sociale à la question raciale?: représenter la société française. Paris: La Découverte, 2006a. p. 133-157.

FASSIN, D. Nommer, interpréter. Le sens commun et la question raciale. In: FASSIN, D.; FASSIN, E. (Dir.). De la question sociale à la question raciale?: représenter la société française. Paris: La Découverte, 2006b. p. 19-36.

FASSIN, D. Quand les corps se souviennent: expériences et politiques du sida en Afrique du Sud. Paris: La Découverte, 2006c.

FASSIN, D. When bodies remember: experiences and politics of AIDS in South Africa. Berkeley: The University of California Press, 2007.

FASSIN, D. Introduction. L'inquiétude ethnographique. In: FASSIN, D.; BENSA, A. (Dir.). Les politiques de l'enquête: épreuves ethnographiques. Paris: La Découverte, 2008a. p. 7-15.

FASSIN, D. Répondre de sa recherche. L'anthropologue face à ses "autres". In: FASSIN, D.; BENSA, A. (Dir.). Les politiques de l'enquête: épreuves ethnographiques. Paris: La Découverte, 2008b. p. 299-320.

FASSIN, D. Another politics of life is possible. Theory, Cutlure and Society, v. 26, n. 5, p. 44-60, 2009a.

FASSIN, D. Une science sociale critique peut-elle être utile? Tracés: Revue de sciences humaines, hors-série, n. 9, p. 199-211, 2009 b.

FASSIN, D. Ethics of survival. A democratic approach to the politics of life. Humanity: An International Journal of Human Rights, Humanitarianism and Development, v. 1, n. 1, p. 91-95, 2010a. 
FASSIN, D. La raison humanitaire: une histoire morale du temps présent. Paris: Hautes Études, Gallimard-Seuil, 2010b.

FASSIN, D. (Dir.). Les nouvelles frontières de la société française. Paris: La Découverte, 2010c.

FASSIN, D. Ni race, ni racisme. Ce que racialiser veut dire. In: FASSIN, D. (Dir.). Les nouvelles frontières de la société française. Paris: La Découverte, 2010d. p. 147-172.

FASSIN, D. Humanitarian reason: a moral history of the present. Berkeley: University of California Press, 2011.

FASSIN, D. Comment j'ai écrit certains de mes textes. In: GROS, F. (Dir.). Cahiers de l'Herne Michel Foucault. No prelo.

FASSIN, D.; PANDOLFI, M. (Ed.). Contemporary states of emergency: the politics of military and humanitarian interventions. New York: Zone Books, 2010 .

FASSIN, D.; RECHTMAN, R. L'empire $d u$ traumatisme: enquête sur la condition de victime. Paris: Flammarion, 2007.

FASSIN, D.; RECHTMAN, R. The empire of trauma: inquiry into the condition of victimhood. Princeton: Princeton University Press, 2009. 